\title{
FACTORS EFFECTING SUCCESSFUL REMOTE MANAGEMENT EFFORTS
}

\author{
Ergin Sait VAROL \\ Istanbul University, Turkey \\ Ertugrul TARCAN \\ Istanbul University, Turkey
}

\begin{abstract}
The aim of this study is to investigate the factors, which have an impact on the success of the remote management efforts and to make the tools enhanced, those of managers on the way of managing remote workers of virtual organizations placed in the service industry.
\end{abstract}

The model used, based on a number of previous studies, and predicts a relationship between antecedents (Technical Support, Supervisor Support, Family Support, Co-Workers Support, and Self-Efficacy) to internal customer satisfaction assessments and their consequence (Job Performance). This model has been tested up using responses from 176 remotely managed employees from the same services of 3 different organizations. The results indicate that the remote employees' of service industry satisfaction assessments do play a serious role in influencing their job performance while some strong relationships have been observed between internal customer satisfaction and the two antecedents including Supervisor Support and Self-Efficacy.

Key words: Remote work, internal customer satisfaction, job performance, service industry

\section{INTRODUCTION}

Recent advances in information technologies led the organizations to diversify their organizational structures that still have some traces of the traditional ways of thinking in management and therefore any such structure shall be the virtual organization of individuals, working toward a common goal, but without traditional characteristics of an organization, the virtual teams being its functional units. Now, many people work in virtual teams that transcend distance, time zones, and organizational boundaries (Lipnack and Stamps, 1997: 1). Virtual teams have all been the groups of working professionals; separated by some geographical and temporal distances. These groups use telecommunication means for business and social communications to satisfy business requirements of the work towards, and to achieve to the common goals.

While there are some clear trends towards the increased complexity in status and potential problems, virtual organization strategies allow organizations to have a great deal of flexibility and greater reliance on advanced technology so as to compete in any rapidly changing business environment. This virtual design has imposed up some unique burdens on communication and management processes, which must be devised in order for organizations to maximize the benefits of these new, virtual structures. The matter of managing remote workers in virtual organizations is critical and needs to be better understood (Staples, Hulland and Higgins, 1999: 759). Consequently, with the rapid growth in virtual structures, researches are clearly in need to understand what managers can do to make their remote workers more effectively. Therefore, we need to learn more about remote management of virtual organizations especially in service industry levels. To meet this need, a model of remote work effectiveness in service management was developed by gathering the existing relevant literature about remote work, remote management, employee satisfaction and service management.

According to Farner, Luthans \& Sommer (2001), Netemeyer, Boles, McKee \& McMurrian (1997) and Eskilden (2000), if organizations are to learn how to increase their employee's satisfaction levels so as to fulfill the relevant remote work tasks, they should make them improved in their performance. To have them in a single model, satisfaction factor can be used for incorporation of a variety of aspects, which are of particular importance in remote work settings. The aspect of Information Technology (IT) for example, appears to have been a key driver for remote work. IT 
allows companies to establish virtual arrangements that facilitate communication and permit greater employee flexibility, without sacrificing managerial control (Freedman, 1993; Handy, 1995; Illingworth, 1994; Lucas and Baroudi, 1994; Mowshowitz, 1994). Also, the aspect of Technical Support (TS) proves to be a strong predictor of satisfaction for telecommuters, therefore establishing effective communication between the manager and employee as found and reported by Fritz, Narasimhan and Rhee (1998).

The human resource managers, generally find management support is the most important aid for the success of a telecommuting program (Ford and McLaughlin, 1995), while supervisor support (SS) can have positive effects on different work outcomes, reducing stress and increasing job satisfaction or coworkers involvement and support can reduce stress and increase job satisfaction and the setting of performance expectations (Babin and Boles, 1996) and family support (FS) will lead to positive telecommuting outcomes (Haines III, Onge, and Archambauld, 2002) as stated by some workers on the point.

Still Bandura, an early writer, (1978: 240) defines self-efficacy (SE) as "a judgment of one's ability to execute a particular behaviour pattern" and according to SE theory, the writer claims that if organizations can learn how to increase their employees SE judgments about their abilities to complete relevant remote work tasks, this learned ability should lead to some performance improvement.

The aspects such as mentioned above, the factorial impacts on remote workers job performance (JP) and on their relation with organization, were closely investigated in this study for a model development, survey data having been collected from 176 remotely managed employees in the service sector, and used to test it.

The research model and related hypotheses appear in the next section, as this paper is organized, the descriptions followed by the presentation of the research methodology employed by a description of the results, and finally by a discussion of the findings including some suggestions over the future research and management up comings.

\section{THE RESEARCH MODEL AND HYPOTHESES}

Based on a review of the literature about the theory and research in organizational science and on the conversations with remote workers in the service sector, a research model was developed as shown in Figure 1. The discussion below was divided into three entries as antecedents to satisfaction, satisfaction and outcome of satisfaction, in order to approach to this model in detail.

The antecedents shown on the left-hand side in Figure 1 represent information from a variety of sources that individuals can use to develop their satisfaction levels. This information effects remote workers' satisfaction level to work remotely. Effectiveness of remote work is represented in the right hand side of the model by an outcome called "JP". We use this model to develop our hypotheses, as follows:

\section{Antecedents Technical Support}

Hartman, Stoner and Arora (1991) found a positive significant correlation between the level of TS received from the supervisor and telecommuting satisfaction. The study conducted by Scott and Timmerman (1999) suggest that the use of more advanced phone technologies is predictive of outcomes such as organizational and occupational identification among telecommuters. Fritz, Narasimhan and Rhee (1998) found that information technology support is a strong predictor of satisfaction with office communication for telecommuters as well as for conventional office workers. Olszewski and Mokhtarian (1994) found that telecommuters have a higher usage of personal computing compared to control group members. Hartman, Stoner and Arora (1991) found that physical requirements that should be met and access to needed equipment as well as access to flexible TS, since distributed employees may work outside regular office hours. Since information technology is a key enabler of the remote work environment, using IT is potentially an important task for effective remote work (Handy, 1995; Illingworth, 1994; Lucas and Baroudi, 1994; Mowshowitz, 1994). In line with previous research, we therefore hypothesize that:

Hypothesis 1 (H1): There is a positive relationship between TS for remote working and internal customer satisfaction (ICS).

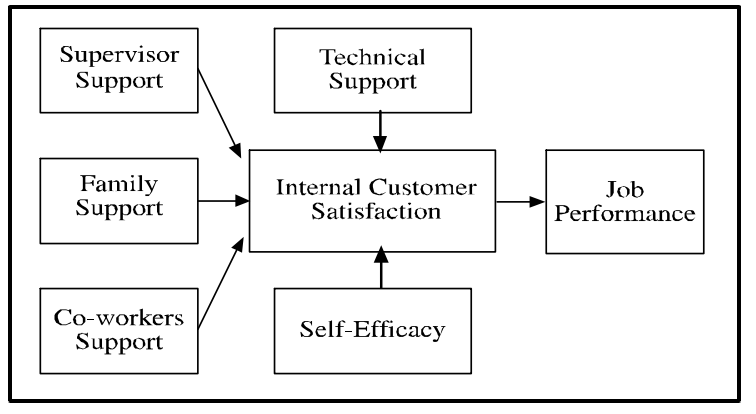

Figure-1: Initial Research Model 


\section{Supervisor Support}

Coaching and giving evaluative feedback on performance, SS that can have positive effects on different work outcomes (Ford and McLaughlin 1995) are common types of social persuasion as Bandura suggested in 1977. Much later Babin and Boles (1996) found that any SS could reduce stress and increase job satisfaction, while Kohli, Shervani and Challagalla (1998) claimed that SS could influence the learning and performance orientations of salespeople.

A positive significant correlation between the level of technical/emotional support from the supervisor and telecommuting satisfaction was described by Hartman, Stoner and Arora (1991), and Handy (1995) and Gordon (1986) showed an agreement on that. SS may be required to manage at a distance, describing it as the support of managing employees with physical presence entrenched in corporate culture and special training. Pancucci (1995) describes supervisors as the managers who must having less frequent contacts with employees, set up specific goals and mile stones, make up regular project reviews and be available for coaching. They must become excellent communicators (Hartman, Stoner and Arora, 1992). As implicated by many workers' reports we conclude that:

Hypothesis $2(\mathrm{H} 2)$ : There is a positive relationship between SS for remote working and ICS.

\section{Family Support}

The transition from a traditional office to telecommuting grounds so reshapes the separation of paid and family work as stated by Shamir and Salomon (1985). To understand what is the effect of telecommuting on work-family balance, we have to look the researches reported whether telecommuting increases or reduces any work-family conflict or generally whether research findings report that telecommuting interferes with work and family balancing are two main problems awaiting to be settled down. A brief review will show that those involved in after hours telecommuting worked more hours and suffered more from overload and spill over of interference from work to family as Duxbury, Higgins and Mills described (1992). On the other hand in another study, Tung, Palvia, Huei, Ye-Meng and Lee (1995) claim that conflicts between work and home were ranked as the third most important drawback of telecommuting. Hill, Miller, Weiner and Colihan (1998) also mention about some Work-life tensions among mobile teleworkers as a reality. Aryee (1992) and Frone, Russell and Cooper (1992) are all in an agreement that any support from the home environment is likely to reduce work-family conflict considerably.
On the contrary Hartman, Stoner and Arora (1991) found that telecommuters who experienced the more family disruptions were the less satisfied ones with their telecommuting experience. Hence, as is easily hypothesized of the conclusion that:

Hypothesis 3 (H3): There is a positive relationship between FS for remote working and ICS.

\section{Co-workers Support}

Babin and Boles (1996) in their research give stress to some key aspects of employees' work environment and to how these perceptions influence work-related outcomes. Their results suggest that the employee perceptions of co-worker involvements can reduce stress and increase job satisfaction. In another study, Stassen, Cameron and Horsburgh (2001) reported that employees perceived significantly lower CWS have lower satisfaction with the amount of work and career future. Thus, it may be well concluded that: Hypothesis 4 (H4): There is a positive relationship between co-workers support (CWS) for remote working and ICS.

\section{Self- efficacy}

In order to work in a virtual environment, people must have self- sufficiency and specific individual skills as well as communication and reliability. Especially if workers are working at home, they must be able to work and solve problems independently. Also they have to have the ability to concentrate in a non-work setting, time management skill and planning capability. Reliability involves working with little face-to-face supervision, and requires self- motivation and selfdiscipline as reported by Bélanger and Collins (1998). Bandura would describe SE as a judgment an individual makes about his or her ability to execute a particular behaviour (Bandura, 1978: 240). The SE theory states that "if organizations can learn how to increase their employees' SE judgments about their abilities to complete relevant remote work tasks, this should lead to improved performance", as pointed out by Staples, Hulland and Higgins (1999: 759). Information on the task activities; achievement, rewards, working conditions and management practices can all have an impact on individuals' perceptions of job satisfaction suggested by Locke (1976), as did Staples (1996) that perceptions of job satisfaction in an environment, would virtually vary depending on the support and activities of management and on the remote individuals' competence in remote work. Positive judgments about one's ability to perform tasks (SE) should have a positive impact on the satisfaction associated with one's doing them (i.e. Job Satisfaction) suggested Staples, Hulland and Higgins (1999) concluding as 
the result of all their findings. So the hypothesize will appear, as a matter of semantics, out of the research reports such as those mentioned above:

Hypothesis 5 (H5): There is a positive relationship between SE for remote working and ICS.

\section{Job Performance}

Companies providing higher satisfaction levels to their internal and external customers have higher economic returns (Aaker \& Jacobson, 1994; Anderson, Fornell \& Lehmann, 1994; Anderson, Fornell \& Rust, 1997; Bolton, 1998; Kennedy \& Schneider, 2000). As empirical works indicated, some researchers attempted to diminish the confusion among customer satisfaction and service quality and the behavioral intentions by determining whether there is any distinction and relationship among them, the attempts mostly turned out, to their satisfaction that there have been significant relationships among these variables (Cronin \& Taylor, 1992; Oliver, 1993; Pothas, Wet \& Wet, 2001; Spreng \& Mackoy's, 1996). Having strong positive effects on his or her retention (Ranaweera and Prabhu, 2003), customers' satisfaction and trust increase revenues, decrease, operating costs and increase profitability (Kanji and Wallace, 2000; Bolton, 1998; Fornell, 1992; Anderson and Fornell, 2000). There is a close relationship between his or her satisfaction and service performance, which in turn would influence his or her business performance (Glynn and Ennis, 2003). Current study advances that JP is influenced by ICS as claimed in the study of Johnston, Parasuraman, Futrell and Black (1990), while some models theorize the reverse: For example Bagozzi (1980) have found that performance directly and positively influences satisfaction. Babin and Boles (1996) have a parallel finding of a positive relationship between JP and job satisfaction and that JP provide a medium for the effects of role stresses on the satisfaction. A conventional wisdom in a country does not make sense in other country. Churchill, Ford and Walker, (1997: 371) say, "As more firms become global competitors, managers must wrestle with the question of whether different characteristics are related to successful sales performance in different countries". According to our country culture, we thought that representatives who have satisfied would work harder and achieve higher levels of performance.

Positive relationship availability between ICS and JP for remote working would have been a conclusive result to the mind, over a brief review of the literature concerned. Hence:

Hypothesis 6 (H6): There is a positive relationship between ICS and JP for remote working.

\section{Power of the model}

In order to test the acceptability and explanatory power of the model, some understandings on the two bases are essential:

Hypothesis 7a (H7a): The level of antecedents (TS, SS, FS, CWS, and SE) explains the level of ICS at a significant level.

Hypothesis 7b (H7b): The level of ICS explains the level of JP at a significant level.

\section{METHODOLOGY AND FINDINGS Survey Questionnaire and Construct Measurement}

Questionnaire contains totally 49 items: 37 items in the five constructs (TS, SS, FS, CWS, and SE) of the first part of the research model; 3 items in the 1 construct (ICS) of the second part; 4 items in the 1 construct (JP) of the third part (see Figure 1); in addition 5 items in the demographic data part.

Answers to all items in the constructs of the model were devised using the same frequency scale (between 1-5), each question having a scaled set of five responses: strongly disagree, disagree, undecided, agree and strongly agree. This scale, in its from negative to affirmative order, resembles to the Likert Scale.

For the first three items in the TS construct were taken from the Mueller and Price (1990) while that for the fourth item in this construct was taken from Staples, Hulland and Higgins (1999). For all items in SS construct were taken from those of Netemeyer et al. (1997: 96), the FS construct items from Haines III, Onge, and Archambauld (2002: 47), and all of the five items in CWS construct from Babin and Boles (1996: 72).

16 items of SE used to create the remote work SE measure, were taken from Staples, Hulland and Higgins (1999). 3 items for ICS construct were retrieved from European Customer Satisfaction Index (ECSI). ECSI has been formed after having the successful results of the Swedish and American customer satisfaction indices. An ECSI pilot study with 55000 interviews in 12 European Countries was performed in 1999. The application of the ECSI model has showed well fitting and sufficiently flexible for different industries (Gronholdt, Martensen and Kristensen, 2000: 510511). And for JP, a construct of 3 items was taken from Haines III, Onge and Archambauld (2002: 47). 


\section{The Sampling Method and Questionnaire Design}

We tested our model and hypotheses on medical representatives that work in the health sector, the biggest one of the service sectors that has been acquiring an increasing importance in global economy. In our study, medical representatives were defined as remote workers in terms of their physical proximity to their managers. In order to investigate the outcomes of our hypotheses, we surveyed the remote workers in three medicine companies. Also these companies chosen randomly from a total of 29 producer and distributor ones in the 7 geographical regions of Turkey. A sample of total 183 medical representatives was chosen from selected companies.

Before the start of application the questionnaire was pre-tested to determine whether any probable problems occur. 176 usable questionnaires were returned (Response rate is 96 percent).

\section{Statistical Analyses}

Statistical analyses were performed using the SPSS software package. Missing values were not included in computing. Analyses were done at the significance level of 0.05 .

For questionnaire constructs, factor analysis wase used in order to decide if items in the constructs could be reduced. "If item deleted" method was also used in analyses for items of the constructs. Cronbach's alpha reliability analysis method was decided to compute the internal consistency values for each of the constructs in the research model. Multicollinearity test has been done to determine if there is collinearity between antecedents of the research model. The hypotheses from $\mathrm{H} 1$ to $\mathrm{H} 6$ were tested computing correlation coefficients using the Spearman Method, and the acceptability and explanatory power of the model were measured using Regression Linear Method (for $\mathrm{H} 7 \mathrm{a}$ and $\mathrm{H} 7 \mathrm{~b}$ ).

\section{Research Analyses Factor Analyses}

Factor analyses used in data reduction were based on all items of the antecedents (TS, SS, FS, CWS, and SE) to ICS. The numbers of the factors and distributions of the items for all constructs (antecedents to ICS, ICS and outcome of ICS) were the same as in the research model except for "SE" one. Factor analysis for the antecedents indicated that the items designed to measure the five independent variables loaded on six separate factors. Varimax Rotation Method was used for the factor rotation. As a result of these analyses SE construct was divided to 2 constructs as SE1 and SE2. After factor analyses, were through, the first research model became as shown in Figure 2.

\section{Reliability Analyses}

The results of the Cronbach's alpha reliability analyses done for each construct in the research model with the items obtained from the factor analyses indicate that all reliability coefficients of the constructs were determined suitable for, and included into the analyses (Cronbach's alpha .909).

\section{Descriptive Statistics and Spearman Correlation Analyses}

Table 1 provides descriptive statistics and correlation coefficients for all constructs of the research model. Because of significantly correlations between constructs, the multicollinearity tests were performed before the regression analyses. And these analyses show that there are not collinearity difficulties for constructs (see Table 1).

Table 1: Descriptive Statistics and Spearman Correlation Coefficients*

\begin{tabular}{|l|l|l|l|l|l|l|l|l|l|l|}
\hline Construct & $\begin{array}{l}\text { Mean } \\
(\mathbf{N = 1 7 6})\end{array}$ & $\begin{array}{l}\text { Stan } \\
\text { dev. }\end{array}$ & TS & SS & FS & CWS & SE1 & SE2 & ICS & JP \\
\hline TS & 3.45 & .91 & 1 & & & & & & & \\
\hline SS & 3.47 & .77 & $.62^{*}$ & 1 & & & & & & \\
\hline FS & 3.30 & .69 & $.60^{*}$ & $.56^{*}$ & 1 & & & & & \\
\hline CWS & 3.24 & .77 & $.56^{*}$ & $.54^{*}$ & $.41^{*}$ & 1 & & & & \\
\hline SE1 & 3.60 & .77 & $.66^{*}$ & $.61^{*}$ & $.53^{*}$ & $.64^{*}$ & 1 & & & \\
\hline SE2 & 4.52 & .57 & $.36^{*}$ & $.37 *$ & $.31^{*}$ & $.50^{*}$ & 1 & & & \\
\hline TCS & 3.41 & .88 & $.67 *$ & $.69^{*}$ & $.57^{*}$ & $.61^{*}$ & $.76^{*}$ & $.48^{*}$ & 1 & \\
\hline JP & 3.73 & .75 & $.67 *$ & $.62^{*}$ & $.51^{*}$ & $.56^{*}$ & $.80^{*}$ & $.51^{*}$ & $.80^{*}$ & 1 \\
\hline
\end{tabular}

* Correlation is significant at the .001 level (2-tailed). 
To statically test H1-H6 hypotheses, we conducted spearmen analysis method. All of the spearman correlation coefficients $\left(r_{\mathrm{sp}}\right)$ of $\mathrm{H} 1$ - H6 obtained from the "Spearman analyses" are statistically significant as seen in Table $1(\mathrm{p}<.001)$. As a result of hypothesis tests, all hypotheses from H1 to H6 were accepted.

\section{The Predictive Power of the Research Model}

Collinearity (or multicollinearity) as indicated by "Variance Inflation Factor (VIF)" values shall be the unfavourable situation where the correlations among the independent variables are strong. Therefore, multicollinearity test for antecedents of the research model was done before testing the explanatory power of the model. Test results with VIF values are given in Table 2, signifying no collinearity among TS, SS, FS, CWS, SE1 and SE2 constructs.

Table 2: The Multicollinearity Values of the Research Model Antecedents

\begin{tabular}{|l|r|r|r|r|r|r|}
\hline Construct & TS & SS & FS & CWS & SE1 & SE2 \\
\hline $\begin{array}{c}\text { Collinearity- } \\
\text { VIF }\end{array}$ & 2.287 & 2.012 & 1.714 & 1.947 & 2.566 & 1.501 \\
\hline
\end{tabular}

Figure- 2: Summary of Path Coefficients and Variances Explained of the Research Model

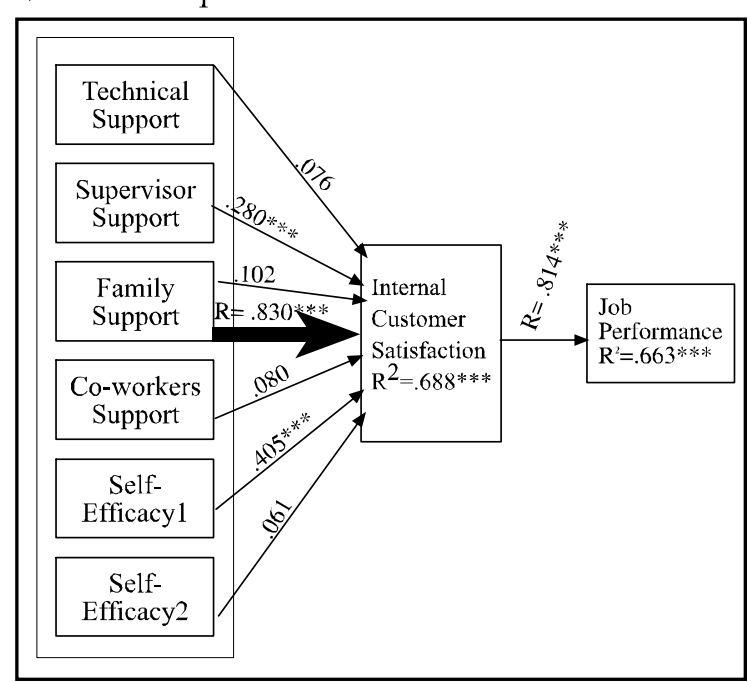

*** Correlation is significant at the .001 level (2Tailed)

Table 3 reports the predictive power of the ICS level.

Table 3: The Predictive Power of the Research Model

\begin{tabular}{|l|l|r|rr|}
\hline Construct & Variance Explained $\left(\mathrm{R}^{2}\right)$ & $\mathrm{df}$ & $\mathrm{F}$ & Sig. \\
\hline ICS & .688 (Adjusted .677) & $6 ; 169$ & 62.157 & .000 \\
\hline JP & .663 (Adjusted .661) & $1 ; 174$ & 341.738 & .000 \\
\hline
\end{tabular}

Figure 2 presents the path coefficients obtained from the regression linear analyses and associated significance levels for each path of the research model. Since the path coefficients between SS and SE1 constructs and ICS construct were statistically significant $(\mathrm{p}<.001)$ (See Figure 2), SS and SE1 were retained as antecedents of the refined model as seen in the Figure 3.

\section{The Predictive Power of the Refined Model}

Before the predictive power test of the refined model, collinearity test was done to see if there was collinearity problem. Collinearity test results for SS and SE1 antecedents of the refined model with VIF values are given in Table 4, signifying no collinearity between SS and SE1 constructs.

Table 4: Collinearity Values of the Refined Model Antecedents

\begin{tabular}{|l|l|l|}
\hline Construct & Supervisor Support & Self Efficacy1 \\
\hline $\begin{array}{l}\text { Collinearity } \\
\text { VIP }\end{array}$ & 1.650 & 1.650 \\
\hline
\end{tabular}

In order to statically test the acceptability and explanatory power of the refined model a Regression Table 5: The Predictive Power of the Refined Model

\begin{tabular}{|l|r|r|r|l|}
\hline Construct & Yariance Explaincd $\left(\mathrm{R}^{2}\right) \mathrm{df}$ & $\mathrm{F}$ & Sig. & \\
\hline $\begin{array}{l}\text { Internal } \\
\text { Customer }\end{array}$ & .665 (Adjusted .662) & $2 ; 173$ & 171.994 & .000 \\
\hline Satisfaction & & & \\
\hline
\end{tabular}

Figure 3 has the path coefficients obtained from the regression of linear analyses and t-values and associated significance levels for each path of the refined model.

Figure- 3: The Summary of Path Coefficients and Variances Explained on the Refined Model

Linear Method was used as shown in Table 5 and Figure 3.

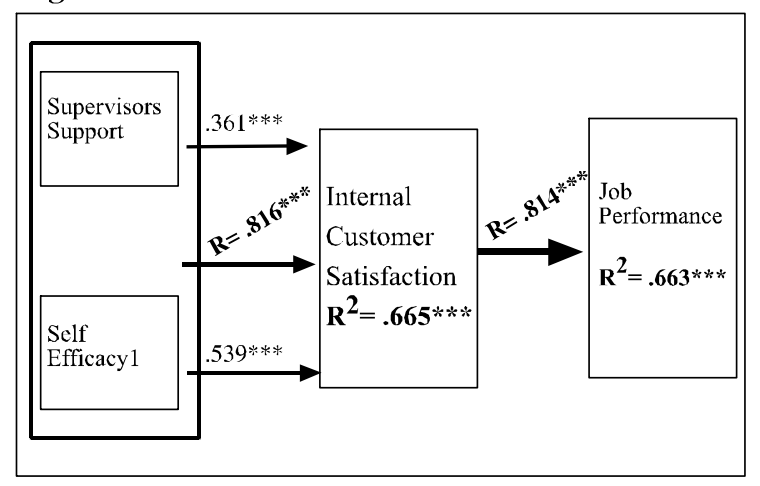

*** Correlation is significant at the .001 level (2Tailed) 


\section{DISCUSSION}

The aim of this current study is to investigate some factors that affect the success of the remote management efforts and enhance tools of managers on the way of managing remote workers in virtual organizations. In order to do this, we investigated the relation between ICS and JP and also the effect of the antecedents (TS, SS, FS, CWS, SE) on ICS, in virtual organizations couched into the service industry (here, medicine distribution). The research used a model that is based on previous researches and predicts relationships between antecedents to ICS assessments and their consequences.

Empirical data offer strong support for the positive main effects of SS and SE1 on ICS and, in turn, ICS on JP.

In the following sub-sections, we shall discuss, duly, the relationship between the antecedents of the ICS and ICS, and the relationship between ICS and the outcome of ICS, the overall predictive power of the model, with a conclusive discussion of the study's limitations, implications for theory, and future researches.

\section{Antecedents and Outcome of Internal Customer Satisfaction}

The hypothesis 1 to 5 was based directly on literature, though related to TS, SS, FS, CWS, SE1 and SE2 constructs, and supported by the results of Spearman Correlation Analyses (See Figure 2, Table 1). Some of these antecedents were removed from the research model after appreciation of the results on "Regression Linear Analyses" (See Figure 3). Initial research model had five ICS antecedents (See Figure 1). According to the results of factor analyses, SE construct has been divided into two, as SE1 and SE2, five antecedents of ICS in the initial model increasing to six in the research model (See Figure 2). This dividing have become conceptually: "SE1", which consist of the items related to the achieving goals and completing tasks and communication with managers and co-workers (remote work self efficacy), and SE2, which represents the items about ability on using and availability of hardware and software possibilities (IT self efficacy). This finding seems appropriate with previous studies: Selfefficacy theory suggests that self-efficacy judgments are relatively task specific (Bandura, 1977, 1978). Then Staples et al. (1999: 760) found that IT selfefficacy and remote work self efficacy were both conceptually and empirically distinct from one another. The results of H1 signify a positive relationship between TS and ICS issues as in the previous studies (for example, Fritz et al., 1998; Hartman et al., 1991; Handy, 1995; Illingworth, 1994; Lucas and Baroudi, 1994; Mowshowitz, 1994; Olszewski and Mokhtarian, 1994; Scott and Timmerman, 1999). But the results of the Regression Linear Analyses related to the research model showed that TS was not strong enough in explaining ICS, so it was dropped out from the research model. A main result of this part of study is that employees who work with face-to-face supervision and remote worker will react differently to an identical job situation because of differences in their comments, which have created different expectations or comparison standards. The reason of non-significant addition of this dropped construct against predictive power of ICS may be this: Remote workers can perceive TS as a necessary and usual condition for remote work.

The result of $\mathrm{H} 2$ shows that there is a significantly positive relationship between SS and ICS and also SS is significant in explaining ICS. Hence, SS is perceived being a considerable tool for managers in increasing of ICS as previous studies (i.e., Babin and Boles, 1996; Ford and McLaughlin, 1995; Gordon, 1986; Handy, 1995; Hartman et al., 1991; Hartman et al., 1992; Kohli et al., 1998; Pancucci, 1995). That shows us, as the landscape of business organizations grows in complexity, the demands for synergism between supervisors and internal customers seems essential. Supervisors do well when they spent time supporting their employees and making sure they are perceived as having upward satisfaction.

Related to the results of $\mathrm{H} 3$, there happens to have been a significantly positive relationship between FS and ICS as previous studies (i.e. Spector, Cooper, and Poelmans, 2004; Haines III, Onge and Archambauld, 2002). But, as the FS did not prove itself to be strong enough to give any explanation to ICS, it was dropped out from the research model. Medical representatives' job more like mobile job than home based one. While telecommuting brings the employee home, mobile work sends him or her away (Kurland and Bailey 1999, Ellison 1999, Sullivan and Lewis 2001). During medical representatives work away from home they don't need FS as well as ones who have home based work. Medical representatives have less relationship with their families than home-based workers have during work hours. Hence FS might not effect on medical representatives' satisfaction level as well as it expected.

Although the result of $\mathrm{H} 4$ shows that there is a significantly positive relationship between CWS and ICS as in the previous studies (for example, Stassen, 
Cameron and Horsburgh, 2001), CWS was dropped from the research model, because CWS is not significant in explaining ICS. The reason of nonsignificant addition of this dropped construct against predictive power of ICS, if it not a remote work, would be reasonably illustrative of satisfaction; but medical representatives' charge intensively depends on individual work. For us, as Money and Graham (1999) pointed out future studies should also address a broader range of constructs, relationships and countries. Particularly interesting would be the effects of CWS in different countries, one might hypothesize a stronger effect on ICS in highly collectivistic countries such as Japan.

The SE1 was retained in the refined model, as the results of H5a shows since there was a significantly positive relationship between SE1 and ICS and also SE1 is significant in explaining ICS. SE1 contains items related to the achieving goals and completing tasks and communication with managers. This result implies that managers should emphasize effective communications between supervisors and employees to increase ICS. Effective communications between supervisors and employees are a significant factor in informing employees of the objectives and job expectations under, particularly, virtual organizations.

The results of $\mathrm{H} 5 \mathrm{~b}$ implied a significantly positive relationship between SE2 and ICS. But SE2 was not strong enough in explaining ICS to any consideration, so it was dropped out from the research model. The reason of non-significant addition of SE2 construct may be this: While SE2 represents the items about ability on using and availability of hardware and software possibilities, remote workers can perceive SE2 as a necessary and usual condition for remote work similar to being in TS.

H6, in its relation between ICS and JP constructs, was supported by the results of Spearman Correlation Analyses (See Table 3 and Figure 2). The result of this analyses showing both that there is a significantly positive relationship between ICS and JP and that ICS is significant in explaining JP, and thus supporting up our model as seen in the previous studies (Johnston et al. 1990; Kanji and Wallace, 2000; Bolton, 1998; Fornell, 1992; Anderson and Fornell, 2000). Overall, the results indicated that remote employees' satisfaction play a critical role in influencing JP in remote work. Because many of these antecedents can be controlled managerially, these findings suggest important ways in which a remote employee's job performance can be enhanced, through the effect of improved ICS in remote work.

\section{Predictive Power of the Model}

Because of the significantly correlations between constructs, the multicollinearity tests were performed before the regression analyses. And these analyses show that there are not collinearity difficulties for constructs.

H7a, relevant to explain the level of ICS through the antecedents, was supported with 68.9 percent (See Table 3 and Figure 2) for the research model. The Regression Linear Analyses results supported SS and SE1 constructs. TS, FS, CWS and SE2 were not supported into any explanatory level for ICS construct. Because of the insignificant path coefficient values (See Figure 2), TS, FS, CWS and SE2 constructs were dropped out from the research model, as seen in the refined model. Although there was a significant relationship between each of these 4 constructs and ICS, these 4 constructs increased in the predictive power of the model only $2.3(68.8-66.5$ as seen in Table 3 and Figure 2) percent.

The degree of variance explained in the ICS construct proved to have been 68.8 percent (See Table 3 and Figure 2 ) in the initial analyses and 66.5 percent (See Table 3 and Figure 3) in the refined model. These measured degrees of variance which support the value of empirical data in literature, sound more reasonable, compared with results of earlier studies over this kind of model. For example Netemeyer et al (1997) reported some 32 percent of the variance in job satisfaction, while Staples et al (1999) found 31.2 percent of the variance in remote work self-efficacy.

Refined model implies that remote workers with more SS and SE1 while working remotely will have higher levels of ICS.

$\mathbf{H} 7 \mathrm{~b}$, related to explain the level of JP through the level of ICS, illuminated 66.3 percent of the issues (See Figure 2 and Figure 3 ) in the research and refined models. Therefore, this refined model implies that remote workers with more ICS while working remotely will have higher levels of JP.

Managers in the service industry, as the results show, should take into consideration the necessity of increasing levels of ICS of remote workers so as to obtain higher JP levels.

Nevertheless, this study has some limitations that offer opportunities for a future research. First, the results are based on the survey of a single service industry. This study should be repeated in different service 
sectors to obtain higher reliable results. Secondly, the applicability of our findings to other contexts needs further research. Responses to the items in the JP construct for future research may be obtained from managers or more objective sources instead of remote workers themselves. Data related to JP were collected from the remote workers, instead of more reliable resources, because firms didn't intent to help in this kind of application during pre-study phase. Third, to raise predictive power of the refined model, new variables are likely be added to this model. Finally, because of some models theorize that performance directly and positively influences satisfaction (Bagozzi, 1980). JP might be one of the antecedents in explaining ICS instead of an outcome of it. So the future studies also might include JP as a predictive variable affecting to ICS.

\section{CONCLUSION}

As a result of rapid changes, global competition, information age and too much travel expenses, many people have been working in virtual organizations. Employee may no longer be co-located or in the same place in order to work together. The employees often work remote from their managers in such organizations. Since this remoteness creates new ways of conducting work, managerial tools have to be enhanced. For this reason, researches are clearly needed on how managers are able to make their remote workers more effective. The study, investigating relationships between the antecedents to ICS assessments and their consequences, intents for help this need to solve this question. Obtained results indicated that remote workers' ICS level, plays a critical role in influencing their JP, the strong positive relationships being observed between ICS and two antecedents called SS and SE. Owing to these antecedents, controllable managerially, all these findings suggest serious ways in which a remote work performance of employee can be improved through the effect of increased remote worker satisfaction level.

Results from this study suggest several important directions for future research. For example, this study should be repeated in different service sectors, data related to JP should be obtained from more objective resources, new variables may be added to the model to reach more reliable results.

While the past studies have focused on External Customer Satisfaction, as a key driver to performance, our study attempt to build up a more complete model of the factors that influence ICS and performance. In addition, our study investigates service management in remote work area. Our study helps, we hope, managers and enhances their tools on the way of managing remote workers of virtual organizations placed in the service industry.

\section{REFERENCES}

Aaker, D.A. and Jacobson, R. (May, 1994), The financial information content of perceived quality, Journal of Marketing Research, Vol. 31, No 2, pp. 191-201.

Anderson, E.W., Fornell, C. and Lehmann, D.R. (July, 1994), Customer satisfaction, market share, and profitability, Journal of Marketing, Vol.58, No 3, pp. 53-66.

Anderson, E.W., Fornell, C. and Rust, R.T. (1997), Customer satisfaction, productivity, and profitability: differences between goods and services, Marketing Science, Vol. 16, No 2, pp. 129-145.

Anderson, E. W. and Fornell, C. (2000), Foundation of the American Customer Satisfaction Index, Total Quality Management, Vol. 11, No 7, pp. S869-S882.

Aryee, S. (1992). Antecedents and outcomes of workfamily conflict among married professional women: Evidence from Singapore, Human Relations, Vol. 45, No 8, pp. 813-837.

Babin, Barry J. and Boles, James S. (1996), The effects of perceived co-worker involvement and supervisor support on service provider role stress, performance and job satisfaction, Journal of Retailing, Vol. 72, No. 1, pp. 57-75.

Bagozzi, R. P. (Spring, 1980), Performance and satisfaction in an industrial sales force: an examination of their antecedents and simultaneity, Journal of Marketing, Vol. 44, No 2, pp. 65-77.

Bandura, Albert (1977), Self-efficacy: Toward a unifying theory of behavioral change, Psychological Review, Vol. 84, No. 2, pp. 191-215.

Bandura, Albert (1978), Reflections on self-efficacy, Advances in Behavioral Research and Therapy, Vol. 1, No. 4, pp. 237-269.

Bélanger, France and Collins, Rosann Webb (1998), Distributed work arrangements: A research framework, The Information Society, Vol. 14, No. 2, pp. 137-152.

Bolton, R.N. (1998), A dynamic model of the duration of the customer's relationship with a continuous service provider: the role of customer satisfaction, Marketing Science, Vol. 17, No 1, pp. 45-65.

Churchill, G.A., N. M. Ford, and Walker, O. C., (1997), Sales Force Management (5th ed.). Homewood Illinois: Richard D. Irwin Inc.

Cronin, J.J. and Taylor, S.A. (1992), Measuring service 
quality: a re-examination and extension, Journal of Marketing, Vol. 56, No 3, pp. 55-68.

Duxbury, L. E., Higgins, C. A. and Mills, S. (1992), After hours telecommuting and work-family conflict: A Comparative analysis, Information Systems Research, Vol.3, No 2, pp. 173-190.

Ellison, N.B., (Fall, 1999), Social impacts- New perspectives on telework, Social Science Computer Review, Vol. 17, No 3, pp. 338-356.

Eskilden, J. K. (December, 2000), A causal model for employee satisfaction, Total Quality Management, Vol. 11, No 8, pp. 1081-1094.

Farner, S., F. Luthans and Sommer, S. M. (2001), An empirical assessment of internal customer service, Managing Service Quality, Vol. 11, No 5, pp 350-358.

Ford, Robert C. and McLaughlin, Frank (1995), Questions and Answers About Telecommuting Programs, Business Horizons, May-June, pp. 66-72.

Fornell, C. (January, 1992), A national customer satisfaction barometer: the Swedish experience, Journal of Marketing, Vol. 56, No 1, pp. 6-21.

Freedman, D. H. (1993), Quick Change Artists, CIO, Vol. 6, No 18, pp. 32-28.

Fritz, Marybeth Watson, Narasimhan, Sridhar and Rhee, Hyeun Suk (1998), Communication and coordination in the virtual office, Journal of Management Information Systems, Vol. 14, No. 4, pp. 7-28.

Frone, M. R., Russell, M. and Cooper, M. L. (1992), Antecedents and outcomes of work-family conflict: Testing a model of the work-family interface, Journal of Applied Psychology, Vol. 77, No 1, pp. 65-78.

Glynn, W.J. and Ennis, S. (2003), Listening practices and performance in service organizations, International Journal of Service Industry Management, Vol. 14, No 3, pp. 310-330.

Gordon, G. E. (1986). Telecommuting: Planning for a new work environment, Journal of Information Systems Management, Vol. 3, No 3, pp. 37-44.

Gronholdt, L., Martensen, A. and Kristensen, K. (2000), The Relationship between customer satisfaction and loyalty: Cross-industry differences, Total Quality Management, Vol. 11, No (4/5\&6), pp. 509-514.

Haines III, Victor Y, St-Onge, Sylvie and Archambauld, Martine (July-Sept. - 2002), Environmental and person antecedents of telecommuting outcomes, Journal of End User Computing. Vol. 14, No. 3, pp. 32-50.
Handy, Charles (1995), Trust and the virtual organization, Harvard Business Review (May-June), pp. $40-50$.

Hartman, Richard I., Stoner, Charles R., and Arora, Raj (1991), An investigation of selected variables affecting telecommuting productivity and satisfaction, Journal of Business and Psychology, Vol. 6, No. 2, pp. 207-225.

Hartman, Richard I., Stoner, Charles R. and Arora, Raj (1992), Developing successful organizational telecommuting arrangements: Worker perception and managerial prescriptions, SAM Advanced Management Journal, Vol. 57, No. 3, pp. 35-42.

Hill, E. J., Miller, B. C., Weiner, S. P. and Colihan, J. (1998). Influences of the virtual office on aspects of work and work/life balance, Personal Psychology, Vol. 51, No 3, pp. 667-683.

Illingworth, M. M. (1994). Virtual Managers, InformationWeek (June 13), pp. 42-58.

Johnston, M.W., Parasuraman, A. , Futrell, C.M. and Black, W.C. (August, 1990), A longitudinal assessment of the impact of selected organizational commitment during early employment, Journal of Marketing Research, Vol. 27, No3, pp. 333-344.

Kanji, G.K. and Wallace, W. (2000), Business excellence through customer satisfaction, Total Quality Management, Vol 11, No 7, pp. S979- S998.

Kennedy, J.M, and Schneider, U. (2000), Measuring customer satisfaction: why, what and how, Total Quality Management, Vol. 11, No 7, pp. S883-S896.

Kohli, Ajay K., Shervani, Tasadduq A. and Challagalla, Goutam N. (1998), Learning and Performance Orientation of Salespeople: The Role of Supervisors, Journal of Marketing Research Vol. 35, No. 2, pp. 263-274.

Kurland, N.B., Bailey, D.E. (Autumn, 1999). The advantages and challenges of working here, there, anywhere, and any time, Organizational Dynamics, Vol. 28, No 2, pp 53-68.

Lipnack, Jessica and Stamps, Jeffrey (1997),Virtual Teams: Reaching Across Space, Time, and Organizations with Technology. N.Y.: John Wiley and Sons, Inc.

Locke, E. A. (1976) The nature and causes of job satisfaction. In M. D. Dunnette (Ed.), Handbook of industrial and organizational psychology (pp.12971349), N.Y.:J.W. \& Sons

Lucas, Henry C. and Baroudi, Jack J. (1994), The role 
of information technology in organization design, Journal of Management Information Systems, Vol.10, No.4, pp.9-23.

Money, R.B. and Graham, J.I. (1999). Salesperson performance, pay, and job satisfaction: Tests of a model using data collected in United States and Japan, Journal of International Business Studies, Vol. 30, No 1, pp 149-172.

Mowshowitz, Abbe (1994), Virtual organizations: A vision of management in the information age, The Information Society, Vol. 10, No. 4, pp. 267-288.

Mueller, C. W. and Price, J. L. (Autumn 1990). Economic, psychological and sociological determinants of voluntary turnover, The Journal of Behavioral Economics, Vol. 19, No 3, pp 321-335.

Netemeyer, R. G., Boles, J. S., McKee, D. O. and McMurrian, R. (July, 1997), An investigation into the antecedents of organizational citizenship behaviours in a personal selling context, Journal of Marketing, Vol. 61, No 3, pp. 85-98.

Oliver, R.L. (1993). A conceptual model of service quality and service satisfaction: compatible goals, different concepts, Advances in Services Marketing and Management, 2, .pp. 65-85.

Olszewski, Piotr and Mokhtarian, Patricia L. (1994), Telecommuting frequency and impacts for state of California employees, Technological Forecasting and Social Change, Vol. 45, No. 3, pp. 275-286.

Pancucci, Dom (1995), Remote control, Management Today, April: pp. 78-80.

Pothas, A. M., Wet, A. G. D., and Wet, J. M. D., (2001), Customer satisfaction: keeping tabs on the issues that matter, Total Quality Management, Vol. 12, No 1, pp. 83-94.

Ranaweera, C. and Prabhu, J. (2003), The influence of satisfaction, trust and switching barriers on customer retention in a continuous purchasing setting, International Journal of Service Industry Management, Vol. 14, No 4, pp 374-395.

Scott, Craig R. and Timmerman, C. E. (1999), Communication Technology Use and Multiple Workplace Identifications among Organizational Teleworkers with Varied Degrees of Virtuality, IEEE Transactions on Professional Communication, Vol. 42 , No. 2, pp. $240-260$.

Shamir, B. and Salomon, I. (1985), Work at home and the quality of working life, Academy of Management Review, Vol. 10, No 3, pp. 455-464.
Spector, P.E., Cooper, C.L. and Poelmans, S. (2004), A cross-national comparative study of work-family stressors, working hours, and well-being: China and Latin America versus the Anglo world, Personnel Psychology, Vol. 57, No 1, pp. 119-142.

Spreng, R.A. and Mackoy, R.D. (1996), An empirical examination of a model of perceived service quality and satisfaction, Journal of Retailing, Vol. 72,No 2, pp. 201-14.

Staples, D. Sandy (1996), An investigation of some key information technology-enabled remote management and remote work issues, Conference Proceedings of the Australasian Conference on Information Systems. University of Tasmania, Hobart.

Staples, D. Sandy, Hulland, John S., and Higgins, Christopher A. (Nov/Dec 1999), A Self- Efficacy Theory Explanation for the Management of Remote Workers in Virtual Organizations, Organizational Science, Vol. 10, No. 6, pp. 758-776.

Stassen, M.A., Cameron, S.J. and Horsburgh, M.E. (2001), Downsizing-initiated job transfer of hospital nurses: How do the job transferees fare?, Journal of Health and Human Services Administration, Vol. 23, No 4, pp. 470-490.

Sullivan, C. and Lewis, S. (April-2001), Home based telework, gender, and the synchronization of work and family: Perspectives of teleworkers and their coresidents, Gender, Work and Organization. Vol. 8, No 2, pp. 123-145.

Tung, L. L., Palvia, S., Huei, L. C., Ye-Meng, L. and Lee, T. M. (1995), Telecommuting in Singapore: Current status and comparison with other countries, Journal of Global Information Management, Vol. 5, No 1, pp. 27-35. 